\title{
MicroRNA-221 and microRNA-222 regulate gastric carcinoma cell proliferation and radioresistance by targeting PTEN
}

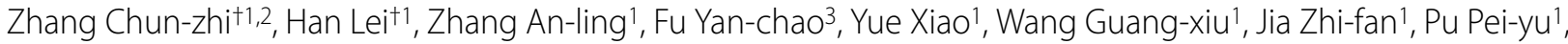 \\ Zhang Qing-yu*3 and Kang Chun-sheng*1
}

\begin{abstract}
Background: MicroRNAs (miRNAs) can function as either oncogenes or tumor suppressor genes via regulation of cell proliferation and/or apoptosis. MiR-221 and miR-222 were discovered to induce cell growth and cell cycle progression via direct targeting of p27 and p57 in various human malignancies. However, the roles of miR-221 and miR-222 have not been reported in human gastric cancer. In this study, we examined the impact of miR-221 and miR-222 on human gastric cancer cells, and identified target genes for miR-221 and miR-222 that might mediate their biology.

Methods: The human gastric cancer cell line SGC7901 was transfected with AS-miR-221/222 or transduced with pMSCV-miR-221/222 to knockdown or restore expression of miR-221 and miR-222, respectively. The effects of miR-221 and miR-222 were then assessed by cell viability, cell cycle analysis, apoptosis, transwell, and clonogenic assay. Potential target genes were identified by Western blot and luciferase reporter assay.

Results: Upregulation of miR-221 and miR-222 induced the malignant phenotype of SGC7901 cells, whereas knockdown of miR-221 and miR-222 reversed this phenotype via induction of PTEN expression. In addition, knockdonwn of miR-221 and miR-222 inhibited cell growth and invasion and increased the radiosensitivity of SGC7901 cells. Notably, the seed sequence of miR-221 and miR-222 matched the 3'UTR of PTEN, and introducing a PTEN cDNA without the 3'UTR into SGC7901 cells abrogated the miR-221 and miR-222-induced malignant phenotype. PTEN-3'UTR luciferase reporter assay confirmed PTEN as a direct target of miR-221 and miR-222.
\end{abstract}

Conclusion: These results demonstrate that miR-221 and miR-222 regulate radiosensitivity, and cell growth and invasion of SGC7901 cells, possibly via direct modulation of PTEN expression. Our study suggests that inhibition of miR221 and miR-222 might form a novel therapeutic strategy for human gastric cancer.

\section{Background}

Gastric cancer, a highly invasive and aggressive malignancy that is characterized by resistance to apoptosis and radioresistance, is among the most common cancers and is the leading cause of cancer-related death in China [16]. Gastric cancer in China is often diagnosed at an advanced clinical stage, with evident lymphatic tumor dissemination [4]. The 5-year survival rate is approxi-

\footnotetext{
*Correspondence: zhangqy@tijmu.edu.cn, kang97061@yahoo.com

1 Department of Neurosurgery, Tianjin Medical University General Hospital and Lab of Neuro-oncology, Tianjin Neurological Institute, Tianjin 300052, China

3 Department of Gastroenterology, Tianjin Medical University General Hospital, Tianjin 300052, China

+ Contributed equally

Full list of author information is available at the end of the article
}

mately $60 \%$ for patients with localized disease, but only $2 \%$ for those with metastatic disease[7]. Although much has been learned about the genetic and biochemical bases of gastric cancer, few novel therapeutic targets have been identified, due to difficulties in target identification and validation.

MicroRNAs (miRNAs) are noncoding RNAs of approximate $22 \mathrm{nt}$ in length that function as post-transcriptional regulators. By base-pairing with the complementary sites in the 3'untranslated region (3'UTR) of the mRNA, miRNAs control mRNA stability and translation efficiency [812]. Growing evidence indicates the important role of miRNA in the development of various cancers. Deregulation of some miRNAs, including miR-221 and miR-222, 
have been observed in lymphoma, colorectal, lung, and breast cancers, papillary thyroid and hepatocellular carcinoma, glioblastoma [13-21], and gastric cancer [22,23].

The PTEN gene, located at 10q23.3, encodes a central domain with homology to the catalytic region of protein tyrosine phosphatases. This gene is an important regulator of protein phosphatases and 3'-phosphoinositol phosphatases. PTEN dephosphorylates phosphatidylinositol3,4,5-triphosphate (PIP3), the second messenger produced by phosphoinositide 3-kinase (PI3K), to negatively regulate the activity of the serine/threonine protein kinase, Akt $[24,25]$. PTEN is inactivated in some malignant tumors, resulting in Akt hyper-activation, thereby promoting cell proliferation, inhibition of apoptosis, and enhanced cell invasion and radioresistance [26-28]. miRNA, specifically miR-21 and miR-214, have been established as regulators of PTEN expression [29-33].

In the current study, we predicted that PTEN would be a target gene of the miR-221 and miR-222 cluster by computer-aided algorithm. Moreover, we found binding sites for human miR-221 and miR-222 in the PTEN 3'-UTR. Based upon these findings, we confirmed PTEN as a target of miR-221 and miR-222, and demonstrated that cosuppression of the miR-221/222 cluster inhibits cell proliferation, induces cell apoptosis, inhibits cell invasion and enhances cell radiosensitivity by upregulating PTEN expression in SGC7901 gastric cancer cells.

\section{Methods}

\section{Cells and cell culture}

The human gastric cancer cell line SGC7901 was kindly provided by Dr. Daiming Fan (the Fourth Military Medical University, China). The human embryonic kidney cell line HEK293 was obtained from the Institute of Biochemistry and Cell Biology, Chinese Academy of Sciences. Cells were grown in Dulbecco's Modified Eagle's medium (DMEM; Gibco, USA) supplemented with $10 \%$ fetal bovine serum at $37^{\circ} \mathrm{C}$ in $5 \% \mathrm{CO}_{2}$ atmosphere.

\section{Identification of microRNA targets}

The PicTar algorithm http://pictar.mdc-berlin.de. was used to identify human microRNA binding sites in PTEN (GeneID 5728). Briefly, PicTar provides 3' UTR alignments with predicted sites and links to various public databases for prediction of microRNA binding sites.

\section{Plasmids, oligonucleotides and cell transfection}

Human full-length miR-221 and miR-222 in pMSCV vector were kindly provided by Reuven Agami (Division of Tumor Biology, The Netherlands Cancer Institute, Amsterdam, Netherlands). The recombinant retroviruses pMSCV-miR-221 and pMSCV-miR-222 were produced as previously described [34], and transfected into PT67, the packaging cells, using Lipofectamine 2000. The titers of homogenous virus were calculated after infection of NIH3T3 cells. Wild-type PTEN lacking the 3'UTR region was constructed in the pcDNA vector (pcDNA-PTEN) by Genesil Biotechnology Co. Ltd. (Wuhan, China). 2'-OMeoligonucleotides were chemically synthesized by GenePharma Co. Ltd. (Shanghai, China). All the bases were 2'OMe modified and had the following sequences: 2'-OMeanti-miR-221 (AS-miR-221), 5'-AGCUACAUUGUCUGCUGGGUUUC-3'; 2'-OMe-anti-miR-222 (AS-miR222), 5'-AGCUACAUCUGGCUACUGGGU-3'; scrambled oligonucleotide (Scr), 5'-UCUA CUCUUUCUAGGAGGUUGUGA-3'.

SGC7901 cells were grown to $70-80 \%$ confluence and transfected with pcDNA- PTEN and 2'-OMe-oligonucleotides using Lipofectamine 2000 or infected with pMSCV-miR-221 and/or pMSCV-miR-222 at a multiplicity of infection (MOI) of 50 at $37^{\circ} \mathrm{C}$. At $4 \mathrm{~h}$ after infection, the medium was replaced with fresh DMEM containing $10 \%$ fetal bovine serum, and the cells were incubated for an additional $72 \mathrm{~h}$ for further study.

\section{Northern blot analysis}

Total RNA was extracted using TRIzol reagent (Invitrogen). The protocol for Northern blotting of miRNA was adopted from Ramkissoon [35]. Total RNA were separated on a $12 \%$ denaturing polyacrylamide gel and transferred to Hybond N+ nylon membrane (Ambion, USA). The membrane was dried, UV cross-linked, hybridized with digoxigenin (DIG)-labeled probes overnight at $37^{\circ} \mathrm{C}$ in a buffer containing $5 \times \mathrm{SSC}, 20 \mathrm{mmol} / \mathrm{L} \mathrm{Na}_{2} \mathrm{HPO}_{4}(\mathrm{pH}$ $=7.2), 7 \%$ SDS, $1 \times$ Denhardt's solution and $0.2 \mathrm{mg} / \mathrm{mL}$ salmon sperm DNA. The specific probes, end-labeled with DIG, were miRNA-221, 5'-GAAACCCAGCAGACAATGTAGCT-3'; miRNA-222, 5'-GAGACC CAGTAGCCAGATGTAGCT-3'; and U6, 5'-ATTTGCGTG TCATCCTTGCG-3'. The probes were purchased from Proligo Primers \& Probes (Sigma, USA). Membranes were washed with $1 \times \mathrm{SSC} / 1 \% \mathrm{SDS}$ at $50^{\circ} \mathrm{C}$. After equilibration in detection buffer, blots were detected with a DIG Luminescent Detection Kit (Roche, USA) and analyzed using GeneGenius.

\section{Cell viability assay}

Cells were seeded into 96 well plates at 4000 cells/well. After transfection, $20 \mu \mathrm{l} \mathrm{MTT}(5 \mathrm{mg} / \mathrm{mL})$ was added into a corresponding test well, and incubated for $4 \mathrm{~h}$. The supernatant was then discarded, and $200 \mu \mathrm{L}$ of DMSO was added to each well to dissolve the precipitate. Optical density (OD) was measured at the wavelength of $570 \mathrm{~nm}$. Each test was performed daily for six consecutive days and repeated in eight wells. 


\section{Cell cycle assay}

For cell cycle analysis, parental and transfected cells in the $\log$ phase of growth were stained with propidium iodide and examined with a fluorescence-activated cellsorting (FACS) flow cytometer (BD Biosciences, San Jose, $\mathrm{CA}$ ), and DNA histograms were analyzed with modified software. Each test was repeated in triplicate.

\section{Measurement of early apoptosis by Annexin V staining}

Parental and transfected cells in the log phase of growth were harvested and collected by centrifugation and resuspended at a density of $1 \times 10^{6}$ cells $/ \mathrm{mL}$. For the apoptosis assay, an annexin V-FITC labeled Apoptosis Detection Kit (Abcam, USA) was used. The pre-labeled cells were detected and apoptosis was quantified using a FACSCalibur flow cytometer (Becton-Dickinson, USA). The data obtained were analyzed using CellQuest software. Each test was repeated in triplicate.

\section{Invasion Assay}

Using parental and transfected cells, the invasion potential of the cells were evaluated by measuring the number of cells invading Matrigel-coated Transwell chambers (Becton Dickinson). Transwell inserts with $8 \mu \mathrm{m}$ pores were coated with Matrigel and reconstituted with fresh medium for $2 \mathrm{~h}$ before the experiment. Cells $\left(2 \times 10^{4} / \mathrm{mL}\right)$ were seeded into the upper chambers in $250 \mu \mathrm{L}$ serum free DMEM, while DMEM supplemented with $10 \%$ fetal bovine serum $(750 \mu \mathrm{L})$ was placed in the lower chamber. Cells were incubated for $72 \mathrm{~h}$. Cells that degraded the Matrigel and invaded the lower surface of the Matrigelcoated membrane were fixed with $70 \%$ ethanol, stained with hematoxylin and counted in five random fields at $\times 200$ magnification under a light microscope. The results were expressed as the average number of invasive cells per field.

\section{Radiation Exposure and Clonogenic assay}

Irradiation was performed at room temperature in a linear accelerator (Varian600, Varian, USA) at a dose rate of 3.2 Gy/min. Cells were plated into six-well plates and exposed to the specified dose (0, 2, 4 and 6 Gy) of X-rays. At $24 \mathrm{~h}$ after irradiation, all cells were trypsinized and counted. Corresponding numbers of cells were seeded into $10 \mathrm{~cm}$ dishes containing DMEM supplemented with $10 \%$ fetal bovine serum in triplicate, incubated for 10-14 days to allow colony growth, and colonies were stained with crystal violet. Colonies containing 50 or more cells were counted. The plating efficiency was calculated by dividing the average number of colonies per dish by the number of cells plated. Survival fractions were calculated by normalization to the plating efficiency of appropriate control groups.

\section{Luciferase reporter assay}

The human 3'-UTR of the PTEN gene was amplified by PCR using the following primers: PTEN-3'UTR-Forward: 5'-CGATTCTAGAAATCATGTTCTGGTGG-3' and PTEN-3'UTR-Reverse: 5'-GCATTCTAGAATTCTGCACAGTAAGCATA-3'. The cDNA was cloned into the $\mathrm{XbaI} / \mathrm{XbaI}$ site of the pGL3-control vector (Promega, USA), downstream of the luciferase gene, to generate the vector pGL3-PTEN. For the luciferase reporter assay, SGC7901 cells were cultured in 96-well plates, transfected with $0.2 \mu \mathrm{g}$ of the pGL3-PTEN or pGL3-control plasmids and 5 pmol of AS-miRNAs (AS-miR-221 and/or AS-miR-222) using Lipofectamine 2000. At $48 \mathrm{~h}$ after transfection, luciferase activity was measured using the Luciferase Assay System (Promega).

\section{Western blot analysis}

Parental and transfected cells were washed with prechilled PBS and solubilized in 1\% Nonidet P-40 lysis buffer. Homogenates were clarified by centrifugation at $20,000 \times \mathrm{g}$ for $15 \mathrm{~min}$ at $4^{\circ} \mathrm{C}$ and the protein concentration was measured by bicinchoninic acid protein assay kit (Pierce Biotechnology). $40 \mu \mathrm{g}$ of protein from each sample was subjected to SDS-PAGE on SDS-acrylamide gel. Separated proteins were transferred to PVDF membranes (Millipore) and incubated with primary antibody (1:1000 dilution; Santa Cruz) followed by incubation with an HRP-conjugated secondary antibody (1:1000 dilution; Zymed, San Diego, CA). The specific protein was detected using a SuperSignal protein detection kit (Pierce, USA). The membrane was stripped and reprobed with a primary antibody against $\beta$-actin (Santa Cruz; 1:1000 dilution) as a control.

\section{Statistical Analysis}

Data are expressed as the mean \pm standard error (S.E.). P $<0.01$ was considered statistically significant using ANOVA and the STD $t$ test or SNK Q test t test.

\section{Results}

\section{Modulation of miR-221 and miR-222 expression in} SGC7901 cell lines

Sequence analysis predicted that miR-221 and miR-222 would regulate PTEN expression. To determine the biologic impact of miR-221 and miR-222 in the SGC7901 gastric cancer line, cells were transfected with AS-miR$221 / 222$ or infected with pMSCV-miR-221/222 to reduce or increase miRNA levels, respectively. Northern blot analysis revealed that the expression of miR-221 and miR-222 was greater in SGC7901 cells than in normal kidney epithelial HEK293 cells (Figure 1A). HEK293 cells were used as negative control in these studies since both HEK293 and SGC7901 cells belong to the epithelial cells 


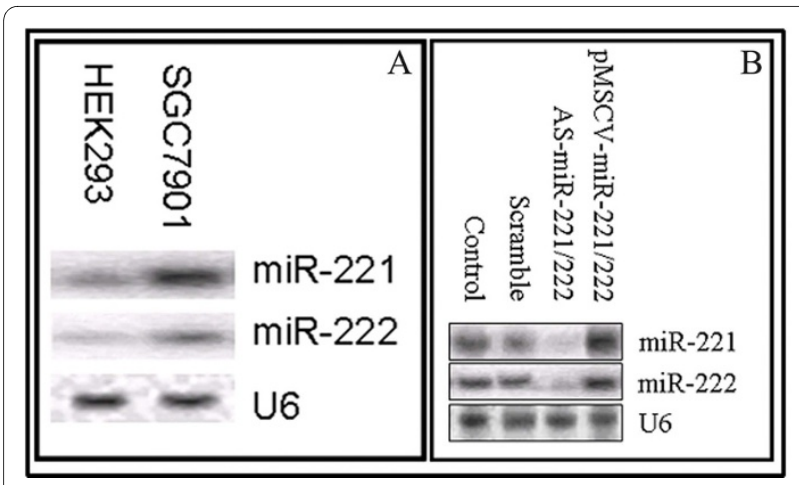

Figure 1 miR-221 and miR-222 expression in SGC7901 and HEK293 cells. Northern blot showing that expression of miR-221 and miR-222 in SGC7901 cells was greater than that in HEK293 cells (Figure 1A). pMSCV-miR-221/222 infection increased the expression of miR221 and miR-222, while AS-miR-221/222 transfection efficiently silenced the expression of miR-221 and miR-222 in SGC7901 cells (Figure 1B).

[36]. Infection of SGC7901 cells with pMSCV-miR-221/ 222 increased miR-221 and miR-222 expression, while transfection with AS-miR-221/222 efficiently silenced miR-221 and miR-222 expression in this cells (Figure 1B). These strategies were then used as the basis of the remaining experiments.

\section{miR-221 and miR-222 co-modulate SGC7901 cell proliferation}

The proliferation rates of SGC7901 cells with enhanced or silenced expression of miR-221 and miR-222 was determined via MTT assay. Compared to control and scramble-transfected cells, cells transfected with ASmiR-221/222 proliferated at a significantly lower rate. In contrast, overexpression of miR-221 and miR-222 by infection with pMSCV-miR-221/222 resulted in significantly enhanced proliferation (Figure 2A). Cell cycle distribution by flow cytometry yielded similar results (Figure 2B). The percentage of control and scramble treated cells in the G0/G1 phase was $38.8 \pm 2.2 \%$ and 45.4 $\pm 1.2 \%$, respectively, while AS-miR-221/222 transfection and pMSCV-miR-221/222 infection resulted in $61.1 \pm$ $3.4 \%$ and $25.1 \pm 0.9 \%$ of cells in G0/G1, respectively. The $\mathrm{S}$ phase fraction in control, scramble, AS-miR-221/222 and pMSCV-miR-221/222 groups were $42.2 \pm 2.3 \%, 36.6$ $\pm 1.7 \%, 23.1 \pm 0.8 \%$ and $58.1 \pm 3.1 \%$, respectively. In sum, transfection with AS-miR-221/222 resulted in the highest percentage of cells in G0/G1 phase ( $p=0.0036)$, and lowest fraction in $S$ phase $(\mathrm{p}=0.0031)$. No statistical significance was observed in the percentage of cells in the G2/ $\mathrm{M}$ phase among the four groups.

Apoptosis is a genetically encoded cascade of cellular reaction that results in the disposal of unwanted cells. Disruption to this pathway has been implicated as a cause of cancer [37]. Some miRNAs regulate proteins that are
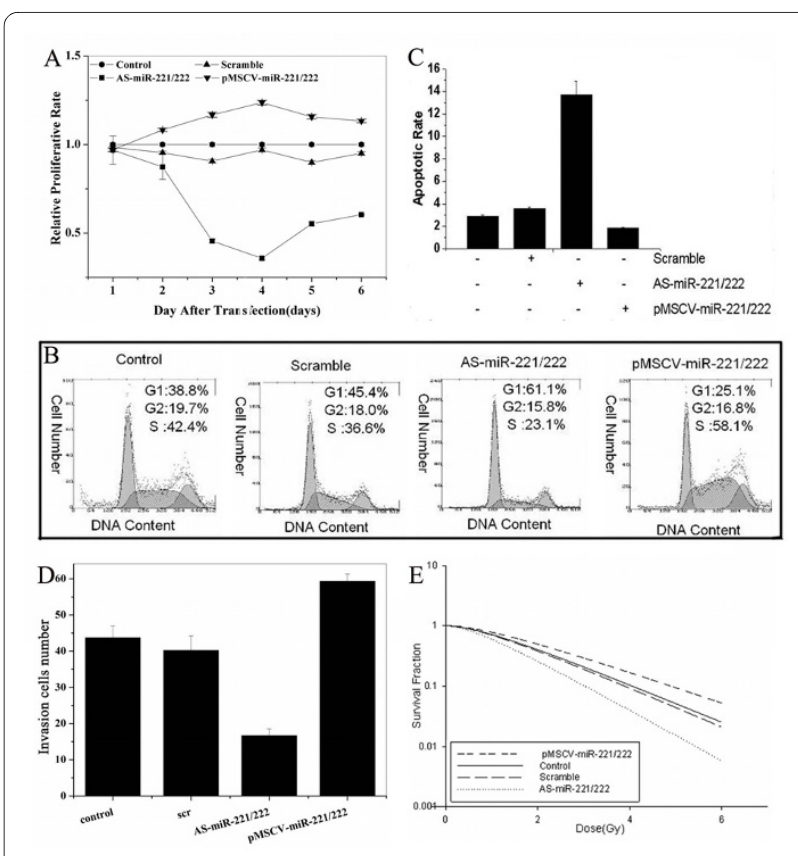

Figure 2 miR-221 and miR-222 affect phenotype of SGC7901 cells. MTT assay showing that cells transfected with AS-miR-221/222 proliferated at a significantly lower rate than controls $(p=0.0023)$. However, the cells infected with pMSCV-miR-221/222 proliferated at a significantly higher rate than controls $(p=0.0311)$ (Figure $2 A)$. Flow cytometry analysis showing that the proportion of cells in the G1 phase in the AS-miR-221/222 group was significantly higher than that in the control group ( $p=0.0036$ ) and that the proportion of cells in the G1 phase in the pMSCV-miR-221/222 group was significantly lower than in the control group $(p=0.0266)$ (Figure $2 B)$. Annexin $V$ analysis showing that the cells transfected with AS-miR-221/222 underwent apoptosis at a significantly higher rate than controls $(p=0.0012)$, while cells infected with pMSCV-miR-221/222 underwent apoptosis at a significantly lower rate than controls $(p=0.0198$ ) (Figure $2 C$ ). Transwell assay showing a decrease in invasive ability in the AS-miR-221/222 group and an increase in the pMSCV-miR-221/222 group compared to controls (Figure 2D). Clonogenic assay indicating that the radiosensitivity of SGC7901 cells increased in the AS-miR-221/222 group ( $p=0.0032$ ) and decreased in the PMSCV-miR-221/222 group compared with controls $(p=0.043)$ (Figure 2E).

involved in apoptosis [38]. Using Annexin V analysis, the number of apoptotic cells in early phase was found to be significantly increased in cells transfected with AS-miR$221 / 222$ compared with that in other groups $(\mathrm{p}=0.0012)$. In comparison with parental cells, the apoptotic rate was very low in pMSCV-miR-221/222 infected cells (Figure $2 \mathrm{C})$. These data demonstrated that the proliferation and survival rates of SGC7901 cells might be co-modulated by miR-221 and miR-222.

\section{miR-221 and miR-222 co-modulate SGC7901 cell invasion}

We also assessed the role of miR-221 and miR-222 on cell invasion by Transwell assay. As shown in Figure 2D, as compared with blank and negative control cells, the invasion potential of SGC7901 cells transfected with AS-miR- 
$221 / 222$ was significantly decreased (0.3813-fold, $\mathrm{p}=$ 0.0067), while cells transduced with pMSCV-miR-221/ 222 displayed markedly increased invasive ability (1.3577-fold, $P=0.0099)$. These results suggested that miR-221 and miR-222 could co-modulate SGC7901 cell invasion.

\section{miR-221 and miR-222 co-modulate SGC7901 cell radiosensitivity}

The national comprehensive cancer network guidelines on gastric cancer treatment include radiotherapy as a standard treatment for patients with a high risk of recurrence http://www.nccn.org/index.asp. To determine whether miR-221 and miR-222 affected SGC7901 cell radiosensitivity, cells were transfected with AS-miR-221/ 222 or infected with pMSCV-miR-221/222 and colony formation was assessed following 0-6 Gy radiation (Figure 2E), Transfection of SGC7901 cells with AS-miRNA221/222 significantly decreased survival following radiation exposure. Conversely, infection of SGC7901 cells with pMSCV-miR-221/222 significantly increased survival following 0-6 Gy compared to blank and negative control. The $\mathrm{D}_{0}$ value, the radiation dose required to reduce the level of cell survival from $100 \%$ to $37 \%$, which is considered a measure of the intrinsic radiosensitivity of the cell, was calculated following genetic manipulation of miR-221/222. Control cells, cells transfected with scrambled oligonucleotides or AS-miRNA-221/222 or cells infected with pMSCV-miR-221/222 exhibited $D_{0}$ values of $1.3897 \mathrm{~Gy}, 1.3326 \mathrm{~Gy}, 1.0358 \mathrm{~Gy}$ and $1.6770 \mathrm{~Gy}$, respectively. The sensitization enhancement ratio (SER), calculated by determining the ratio of the $\mathrm{D}_{0}$ of the control group $v s$. treated cells, was 1.0428, 1.3417 and 0.8287 for scramble-, AS-miRNA-221/222-, or pMSCV-miR-221/ 222-treated cells, respectively (Table 1). Collectively, these results provide strong evidence that miRNA-221/ 222 co-regulates the radiosensitivity of SGC7901 cells.

\section{miR-221 and miR-222 targeting of the PTEN gene}

Using bioinformatics analysis, we found that miR-221 and miR-222 contained specific binding sequences for the 3'UTR region of the PTEN gene. To confirm that PTEN is a target of miR-221 and miR-222, we cloned the PTEN 3'UTR fragment containing the putative miR-221/ 222 target site into pGL3-control vector with a luciferase reporter gene (pGL3-PTEN). As shown in Figure 3A, cotransfection of AS-miR-221/222 with pGL3-PTEN significantly enhanced luciferase activity compared to scramble or control treated cells $(\mathrm{p}=0.0011)$. Furthermore, Western blot analysis showed that PTEN was significantly upregulated in AS-miR-221/222 transfected cells. In contrast, PTEN expression was downregulated in pMSCV-miR-221/222 infected cells (Figure 3B). Together, these data demonstrated that PTEN is a target gene of the miR-221/222 cluster.

\section{miR-221 and miR-222 affect the phenotype of SGC7901 cell} in a PTEN-dependent pattern

To determine the role of PTEN in miR-221 and miR-222 co-regulation of the SGC7901 phenotype, cells were transfected with pcDNA-PTEN. We observed a similar phenotype in pcDNA-PTEN transfected cells as observed in cells transfected with AS-miR-221/222, including decreased viability, enhanced apoptosis, prolonged G0/ G1 phase transition, and reduced cell invasive capacity (Figure 4A-E). As the pcDNA-PTEN construct does not include the 3'UTR region of PTEN, transduction SGC7901 cells with both pcDNA-PTEN and pMSCVmiR-221/222 had no impact on viability, apoptosis, cell cycle progression, and invasive ability compared to transfection with pcDNA-PTEN alone (Figure 4A-E and Table 2). These results define an important role for PTEN as a mediator of the biological effects of miR-221/222 in SGC7901 gastric cancer cells.

PTEN is a tumor-suppressor gene and its role in tumor biology is well-characterized [39]. Inactivation of PTEN activates the serine/threonine protein kinase, Akt. Moreover, pAkt is a crucial protein involved in the regulation of cell-cycle progression, cell survival, apoptosis, invasion and radiosensitivity. Using Western blot analysis, we observed that the expression of PTEN was increased and the expression of pAkt was decreased in AS-miR-221/222

Table 1: Impact of miRNA221/222 expression on SGC7901 cell radiosensitivity.

\begin{tabular}{|c|c|c|c|c|}
\hline Group & $\mathbf{D}_{0}$ & $\mathbf{D}_{\mathrm{q}}$ & $\mathbf{S F}_{2}$ & SER \\
\hline control + irradiation & 1.3897 & 2.6293 & 0.3865 & \\
\hline Scrambled + irradiation & 1.3326 & 2.5213 & 0.3639 & 1.0428 \\
\hline AS-miRNA221/222 + irradiation & 1.0358 & 1.9597 & 0.25 & 1.3417 \\
\hline pMSCV-miR-221/222 + irradiation & 1.677 & 3.1729 & 0.4536 & 0.8287 \\
\hline
\end{tabular}

SGC7901 cells were transfected with scrambled or AS-miRNA221/222 or infected with pMSCV-miR-221/222. $D_{0}$ and $D_{q}$ were determined by standardized software, and the sensitization enhancement ratio (SER) was calculated by determining the ratio of the $D_{0}$ of the control group vs. treated cells. 


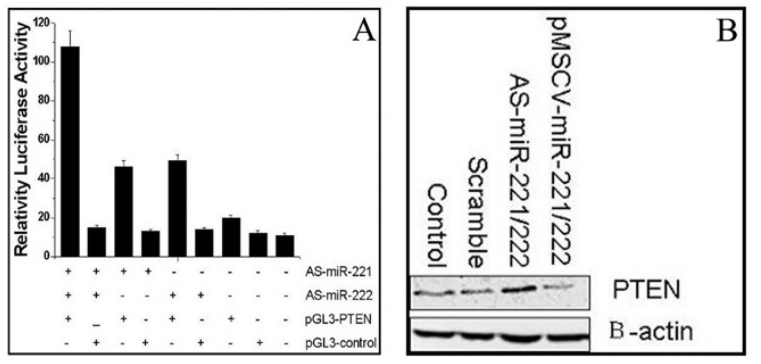

Figure 3 PTEN is a target gene of miR-221 and miR-222. pGL3PTEN construct containing PTEN 3'UTR was transfected into SGC7901 cells previously transfected with AS-miR-221 and/or AS-miR-222. Luciferase activity was determined $48 \mathrm{~h}$ after transfection. The ratio of normalized sensor to control luciferase activity is shown. Error bars represent the standard deviation and were obtained from three independent experiments (Figure 3A). Western blot analysis demonstrating that PTEN expression was significantly enhanced in AS-miR-221/222 treated cells, and significantly downregulated in the pMSCV-miR-221/ 222 infected group compared to controls (Figure 3B).

transfected SGC7901 cells compared to controls. Furthermore, infection of SGC7901 cells with pMSCV-miR221/222 resulted in decreased PTEN and increased pAkt expressions (Figure 5). In addition, the expression of cyclin D, Bcl-2, MMP2 and MMP9, all of which are regulated by pAkt, were downregulated in the AS-miR-221/ 222 group and slightly upregulated in the pMSCV-miR$221 / 222$ group. These data suggest that miR-221 and miR-222 impact the phenotype of SGC7901 cell by modulating the expression of PTEN and Akt phosphorylation.

\section{Discussion}

In this study, we demonstrated that miR-221 and miR222 regulate gastric cancer cell viability, apoptosis, cell cycle progression and invasive ability. Our data suggests that downregulation of PTEN expression and enhanced Akt phosphorylation (p-Akt) are important mediators of these cellular processes. As pAkt impacts cell proliferation, cell transit from the G0/G1 to the S phase, apoptosis, cell invasive ability, and cell radiosensitivity, downregulation of miR-221 and miR-222 expression have important biologic effects on the malignant phenotype of SGC7901 cells. These results identify AS-miR-221/222 as a potential therapeutic approach for gastric cancer via upregulation of PTEN.

PTEN functions as a tumor suppressor gene, specifically by negatively regulating the Akt/PKB signaling pathway. Genetic inactivation of PTEN is a hallmark of many cancers, including glioblastoma, endometrial and prostate cancers, and reduced expression occurs in many other tumor types. Deficiency of PTEN in the intestine has been reported to induce precancerous polyps, via the induction of formation and fission of crypts, structures located at the base of the intestine containing a rapidly dividing pool of intestinal stem cells [40]. Guo JM et al studied the microRNAs expression in primary gastric cancer tissues via microRNA microarray assay and were the first to demonstrate that PTEN was the target of miR21 [41]; however, little is known regarding the impact of miR-221 and miR-222 on PTEN expression in gastric cancer.

miR-221 and miR-222 expression is abnormally increased in gastric cancer [42], however the mechanism by which miR-221 and miR-222 modulates tumor progression within the gut remains unknown. Here, we observed miR-221 and miR-222 upregulation in the human gastric cancer cell line SGC7901 compared with HEK293 epithelial cells, corroborating the findings of Young-kook et al [23]. miR-221 and miR-222 modulate a variety of biological functions in the SGC7901 cell, including cell proliferation, apoptosis, invasion, and radioresistance. We identified binding sites for miR-221 and miR-222 in the PTEN 3'-UTR by bioinformatics analysis, suggesting that increased expression of the miR-221/ 222 cluster might impact on PTEN expression. Indeed, we demonstrated that PTEN is a target gene of miR-221 and miR-222 by luciferase reporter assay. As PTEN can antagonize PI3K activity by dephosphorylating PIP3 and thereby negatively regulates the activity of Akt pathway $[24,25]$. Several studies suggest that the loss of the PTEN function might be the underlying factor in Akt pathway activation [43-45]; thus, our findings are consistent with an emerging body of literature.

Akt represents a subfamily of the serine/threonine kinase family [46]. It modulates the function of numerous substrates related to the cell proliferation, apoptosis and

Table 2: Impact of PTEN on miRNA221/222-mediated SGC7901 cell radiosensitivity.

\begin{tabular}{ccccc}
\hline Group & $\mathbf{D}_{\mathbf{0}}$ & $\mathbf{D}_{\mathbf{q}}$ & $\mathbf{S F}_{\mathbf{2}}$ & $\mathbf{S E R}$ \\
\hline control +irradiation & 1.6031 & 3.0331 & 0.4566 & \\
pcDNA-PTEN +irradiation & 1.0719 & 1.6422 & 0.2230 & 1.4956 \\
AS-miR-221/222 +irradiation & 1.0723 & 1.6428 & 0.2436 & 1.4950 \\
pMSCV-miR-221/222 and pcDNA-PTEN + irradiation & 1.1303 & 1.7316 & 0.2630 & 1.4183 \\
\hline
\end{tabular}

SGC7901 cells were transfected with pcDNA-PTEN or AS-miRNA221/222 or infected with pMSCV-miR-221/222 and transfected with pcDNA-

PTEN. DO, Dq and SER were determined as described in Table 1. 

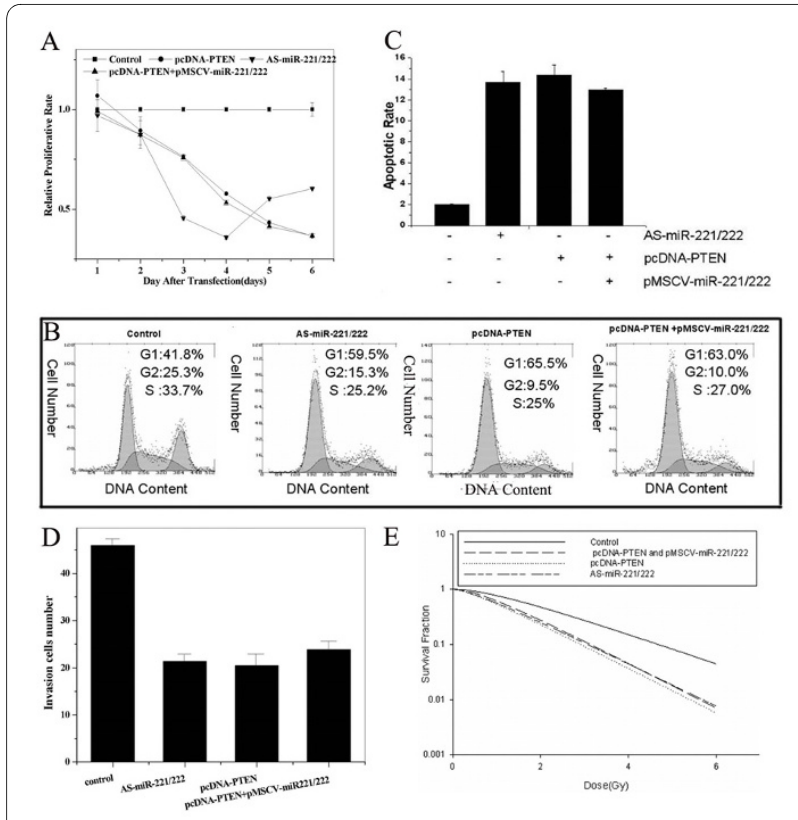

Figure 4 PTEN regulates the impact of miR-221/222. SGC7901 cells were cultured and treated with pcDNA-PTEN, AS-miR-221/222, or pMSCV-miR-221/222, and subjected to MTT assay. Transfection with pcDNA-PTEN increased cell proliferation to a similar rate as cells transfected with AS-miR-221/222. Infection of pcDNA-PTEN-treated cells with pMSCV-miR-221/222 had no effect on proliferation (Figure 4 A). Flow cytometry analysis showing that the fraction of cells in G1 phase following AS-miR-221/222 transfection was significantly higher than in the control. Transfection with pCDNA-PTEN resulted in statistically similar results as with AS-miR-221/222, and infection of pcDNAPTEN transduced cells with pMSCV-miR-221/222 did not impact on cell cycle progression (Figure 4B). Annexin $V$ staining and flow cytometry analysis showing that AS-miR-221/222 transfection induced significantly higher levels of apoptosis in SGC7901 cells than controls, and transfection with pCDNA-PTEN yielded similar results. Infection of pcDNA-PTEN-transfected cells with pMSCV-miR-221/222 did not impact on apoptosis (Figure 4C). Transwell assay showing that AS-miR-221/ 222 transfection decreased invasive ability compared to controls. Transfection with pcDNA-PTEN yielded similar results, and infection of pcDNA-PTEN-transfected cells with pMSCV-miR-221/222 did not impact on invasive ability. Data represents the number of migrated cells per field (Figure 4D). AS-miR-221/222 and pcDNA-PTEN transfection increased radiosensitivity, as determined by clonogenic assay following radiation exposure. Infection of pcDNA-PTEN-transfected cells with pMSCV-miR-221/222 did not impact clonogenic survival. Experiments were performed in triplicate. When applicable, data is represented as mean \pm SE (Figure 4E).

invasion and is putatively involved in the development of some cancers, such as in colon [47], prostate [48], lung [49] and thyroid cancer [50]. It has been shown that Akt activation in cancer cells can increase their invasive ability and resistance to radiotherapy [51-53]. In our study, we found that knockdown of miR-221 and miR-222 in SGC7901 cells resulted in downregulation of pAkt expression, affecting the expression of several Akt-regulated proteins including cyclin D1, Bcl-2, and MMP2/9.

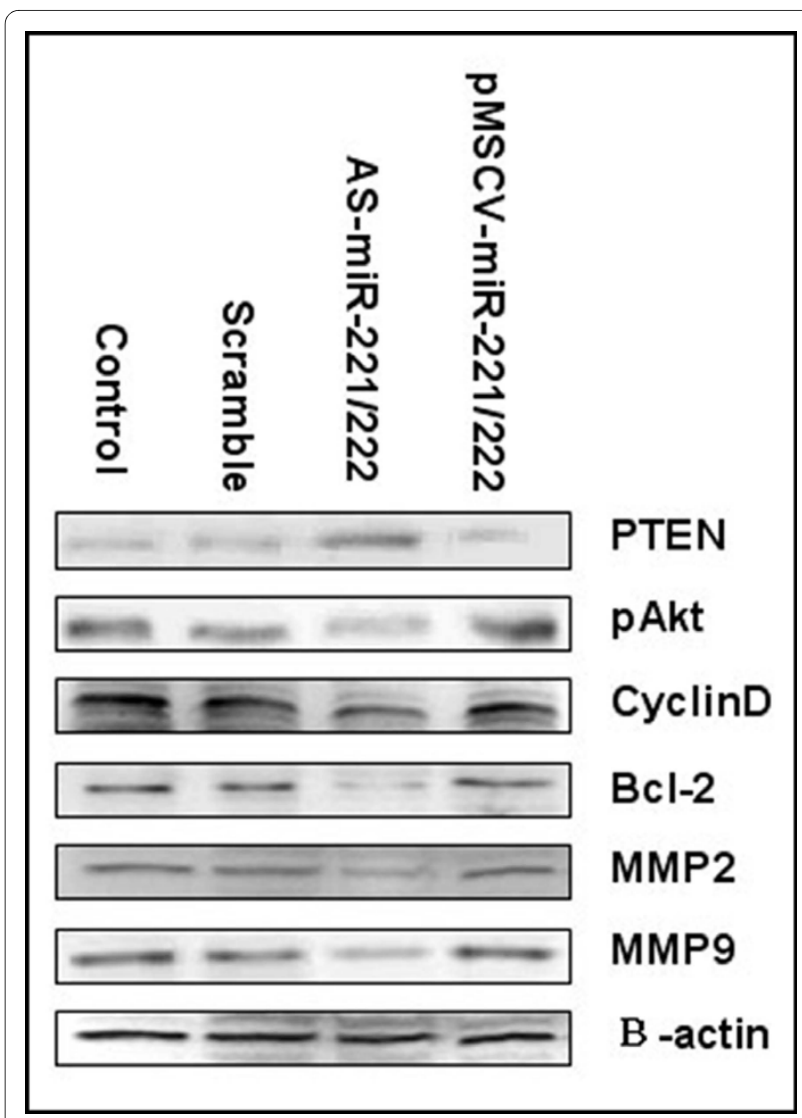

Figure 5 Impact of miR-221/222 on protein expression in the Akt pathway. Western blot analysis of SGC7901 cell lysates following genetic modulation of miR-221/222 expression with AS-miR-221/222 or pMSCV-miR-221/222. miR-221/222 inversely correlates with PTEN expression and positively correlates with pAkt, cyclinD, Bcl-2, and MMP2/ 9. $\beta$-actin was used as negative control.

The malignant phenotype of the SGC7901 cells was reversed by knockdown miR-221 and miR-222, and cells were sensitized to radiation, corroborating the results of Garofalo et al [54]. As PTEN is a target of miR-221 and miR-222, and has been described previously as an important regulator of radiation sensitivity $[24,55]$, these results suggest that increasing PTEN expression by silencing miR-221/222 could enhance the radiosensitivity of SGC7901 cells. Whether PTEN/Akt signaling is the sole target for miRNA-221/222 regulation of radiosensitivity remains unknown.

While our work identifies a role for PTEN in miRNA221/222-induced biology, it remains possible other factors might be at least partially involved. Negative regulation of p27 and p57 by miRNA221/222 might also contribute to radioresistance [56], however they are more likely to contribute to cell proliferation and viability $[57,58]$. Moreover, TIMP3, as a target of miR-221 and miR-222, might also affect cell invasion[54]. In sum, our results suggest that inhibition of the miR221/222 cluster 


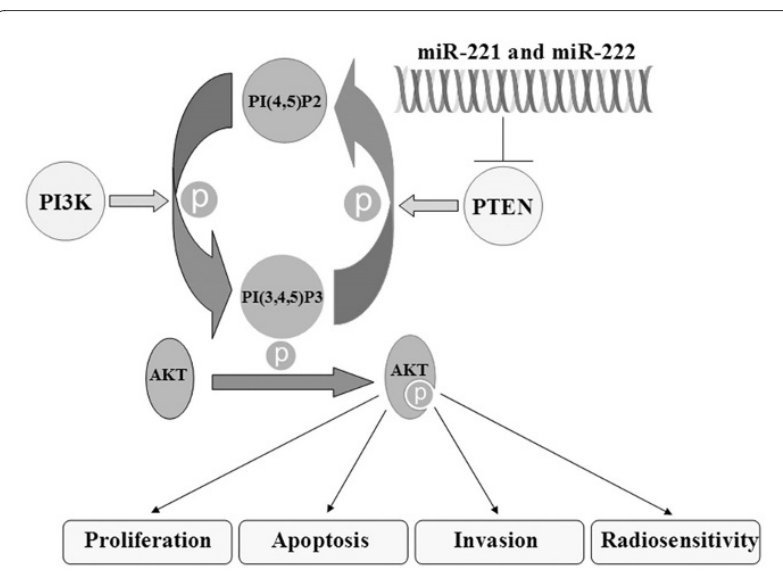

Figure 6 miR-221/222-mediated regulation of signal transduction via PTEN. Hypothetical representation of the role of miR-221 and miR-222 in regulation of Akt phosphorylation and downstream signaling of proliferation, apoptosis, invasion, and radiosensitivity via PTEN. Our data supports an essential role for miR-221/222 in the inhibition of PTEN, thereby promoting Akt phosphorylation via activated PIP3.

represents a molecular therapeutic approach that impacts on multiple genes involved in anti-tumor growth and radiosensitization, as summarized in Figure 6.

\section{Conclusions}

The PTEN gene is an important functional target of the miR-221/222 cluster in gastric cancer cells. Modulation of miR-221/222 expression by antisense or overexpression strategies directly affected PTEN expression. At present, anti-miRNA oligonucleotides have been shown to specifically inactivate endogenous target miRNAs, although rather inefficiently $[59,60]$. We provide evidence that co-suppression of both miR-221 and miR-222 affects gastric cancer cell biology in vitro, and might represent a novel therapeutic strategy for gastric cancer through upregulation of PTEN expression.

\section{Competing interests}

The authors declare that they have no competing interests.

\section{Authors' contributions}

KCS conceived the project. ZCZ and HL carried out all the studies, analyzed the data, and wrote the first draft of the paper. ZCZ, HL, ZQY, ZAL, FYC, YX, WGX, JZF, PPY and KCS were involved in experimental design. ZQY provided guidance with the study and assisted with the manuscript draft. PPY and KCS helped in carrying out the experiments. ZAL, FYC and YX carried out the Northern blot and Western blot analysis. FYC carried out the cell viability and apoptosis assay. YX carried out the cell cycle and invasion assay. WGX carried out the clonogenic and luciferase reporter assay. JZF conducted analyses of expression data. All authors read and approved the final manuscript.

\section{Acknowledgements}

This work was supported by the China National Natural Scientific Fund (30772231), the Tianjin Science and Technology Committee (10JCZDJC18500), the Program for New Century Excellent Talents in University (NCET-07-0615). The authors wish to thank Dr. R Agami, Division of Tumor Biology, the Netherlands Cancer Institute, Amsterdam, the Netherlands, for kindly providing the retroviral constructs of miR-221 and miR-222. The authors also wish to thank
Dr. Daiming Fan, the Fourth Military Medical University, China, for kindly providing SGC7901 gastric cancer cells.

\section{Author Details}

'Department of Neurosurgery, Tianjin Medical University General Hospital and Lab of Neuro-oncology, Tianjin Neurological Institute, Tianjin 300052, China, 2Department of Radiation Oncology, Tianjin Huan Hu Hospital, Tianjin 300060, China and ${ }^{3}$ Department of Gastroenterology, Tianjin Medical University General Hospital, Tianjin 300052, China

Received: 6 January 2010 Accepted: 12 July 2010

Published: 12 July 2010

\section{References}

1. Yu HG, Ai YW, Yu LL, Zhou XD, Li JH, Xu XM, Liu S, Chen J, Liu F, Qi YL, Deng QJ, Cao J, Liu SQ, Luo HS, Yu JP: Phosphoinositide 3-kinase/Akt pathway plays an important role in chemoresistance of gastric cancer cells against etoposide and doxorubicin induced cell death. Int J Cancer 2008, 122:433-443.

2. Qiu H, Yashiro M, Shinto O, Matsuzaki T, Hirakawa K: DNA methyltransferase inhibitor 5 -aza-CdR enhances the radiosensitivity of gastric cancer cells. Cancer Sci 2009, 100:181-188.

3. Cinti C, Vindigni C, Zamparelli A, La Sala D, Epistolato MC, Marrelli D, Cevenini G, Tosi P: Activated Akt as an indicator of prognosis in gastric cancer. Virchows Arch 2008, 453:449-455.

4. Bandres E, Bitarte N, Arias F, Agorreta J, Fortes P, Agirre X, Zarate R, DiazGonzalez JA, Ramirez N, Sola JJ, Jimenez P, Rodriguez J, Garcia-Foncillas J: microRNA-451 regulates macrophage migration inhibitory factor production and proliferation of gastrointestinal cancer cells. Clin Cancer Res 2009, 15:2281-2290.

5. Lee BL, Lee HS, Jung J, Cho SJ, Chung HY, Kim WH, Jin YW, Kim CS, Nam SY: Nuclear factor-KB activation correlates with better prognosis and Akt activation in human gastric cancer. Clin Cancer Res 2005, 11:2518-2525

6. Cai SR, Wang Z, Chen CQ, Wu WH, He YL, Zhan WH, Zhang CH, Cui J, Wu H: Role of silencing phosphatase of regenerating liver-3 expression by microRNA interference in the growth of gastric cancer. Chin Med J 2008, 121:2534-2538.

7. Rojo F, Tabernero J, Albanell J, Van Cutsem E, Ohtsu A, Doi T, Koizumi W, Shirao K, Takiuchi H, Ramon y Cajal S, Baselga J: Pharmacodynamic studies of gefitinib in tumor biopsy specimens from patients with advanced gastric carcinoma. J Clinical Oncology 2006, 24:4309-4315.

8. Liu T, Tang H, Lang Y, Liu M, Li X: MicroRNA-27a functions as an oncogene in gastric adenocarcinoma by targeting prohibitin. Cancer Letters 2008, 273:233-242.

9. Moriyama T, Ohuchida K, Mizumoto K, Yu J, Sato N, Nabae T, Takahata S, Toma H, Nagai E, Tanaka M: MicroRNA-21 modulates biological functions of pancreatic cancer cells including their proliferation, invasion and chemoresistance. Mol Cancer Ther 2009, 8:1067-1074.

10. Selbach M, Schwanhäusser B, Thierfelder N, Fang Z, Khanin R, Rajewsky N: Widespread changes in protein synthesis induced by microRNAs. Nature 2008, 455:58-63.

11. Tay Y, Zhang J, Thomson AM, Lim B, Rigoutsos I: MicroRNAs to Nanog, Oct4 and Sox 2 coding regions modulate embryonic stem cell differentiation. Nature 2008, 455:1124-1128.

12. Chi SW, Zang JB, Mele A, Darnell RB: Argonaute HITS-CLIP decodes microRNA-mRNA interaction maps. Nature 2009, 460:479-486.

13. Calin GA, Croce CM: MicroRNA signatures in human cancers. Nature Reviews Cancer 2006, 6:857-866.

14. Metzler M, Wilda M, Busch K, Viehmann S, Borkhardt A: High expression of precursor microRNA-155/BIC RNA in children with Burkitt lymphoma. Genes Chromosomes Cancer 2004, 39:167-169.

15. Michael MZ, O' Connor SM, van Holst Pellekaan NG, Young GP, James RJ: Reduced accumulation of specific microRNAs in colorectal neoplasia. Mol Cancer Res 2003, 1:882-891.

16. Takamizawa J, Konishi H, Yanagisawa K, Tomida S, Osada H, Endoh H, Harano T, Yatabe Y, Nagino M, Nimura Y, Mitsudomi T, Takahashi T: Reduced expression of the let-7 microRNAs in human lung cancers in association with shortened postoperative survival. Cancer Res 2004 64:3753-3756 
17. Iorio MV, Ferracin M, Liu CG, Veronese A, Spizzo R, Sabbioni S, Magri E, Pedriali M, Fabbri M, Campiglio M, Ménard S, Palazzo JP, Rosenberg A, Musiani P, Volinia S, Nenci I, Calin GA, Querzoli P, Negrini M, Croce CM: MicroRNA gene expression deregulation in human breast cancer. Cancer Res 2005, 65:7065-7070.

18. He H, Jazdzewski K, Li W, Liyanarachchi S, Nagy R, Volinia S, Calin GA, Liu CG, Franssila K, Suster S, Kloos RT, Croce CM, Chapelle A: The role of microRNA genes in papillary thyroid carcinoma. PNAS 2005, 102:19075-19080.

19. Murakami Y, Yasuda T, Saigo K, Urashima T, Toyoda H, Okanoue T, Shimotohno K: Comprehensive analysis of microRNA expression patterns in hepatocellular carcinoma and non-tumorous tissues. Oncogene 2006, 25:2537-2545.

20. Chan JA, Krichevsky AM, Kosik KS: MicroRNA-21 is an antiapoptotic factor in human glioblastoma cells. Cancer Res 2005, 65:6029-6033.

21. Ciafrè SA, Galardi S, Mangiola A, Ferracin M, Liu CG, Sabatino G, Negrini M, Maira G, Croce CM, Farace MG: Extensive modulation of a set of microRNAs in primary glioblastoma. Biochem Biophys Res Commun 2005, 334:1351-1358.

22. Volinia S, Calin GA, Liu CG, Ambs S, Cimmino A, Petrocca F, Visone R, lorio M, Roldo C, Ferracin M, Prueitt RL, Yanaihara N, Lanza G, Scarpa A, Vecchione A, Negrini M, Harris CC, Croce CM: A microRNA expression signature of human solid tumors defines cancer gene targets. PNAS 2006, 103:2257-2261.

23. Kim YK, Yu J, Tae SH, Park SY, Bumjin N, Dong HK, Keun H, Yoo MW, Lee HJ, Yang HK, Kim VN: Functional links between clustered microRNAs: suppression of cell-cycle inhibitors by microRNA clusters in gastric cancer. Nucleic Acids Research 2009, 37:1672-1681.

24. Sun Y, St Clair DK, Fang F, Warren GW, Rangnekar VM, Crooks PA, St Clair WH: The radiosensitization effect of parthenolide in prostate cancer cells is mediated by nuclear factor-KB inhibition and enhanced by the presence of PTEN. Mol Cancer Ther 2007, 6:2477-2486.

25. Jiang Z, Pore N, Cerniglia GJ, Mick R, Georgescu MM, Bernhard EJ, Hahn SM, Gupta AK, Maity A: Phosphatase and tensin homologue deficiency in glioblastoma confers resistance to radiation and temozolomide that is reversed by the protease inhibitor nelfinavir. Cancer Res 2007 67:4467-4473.

26. Ge H, Cao YY, Chen LQ, Wang YM, Chen ZF, Wen DG, Zhang XF, Guo W, Wang N, Li Y, Zhang JH: PTEN polymorphisms and the risk of esophageal carcinoma and gastric cardiac carcinoma in a high incidence region of China. Diseases of the Esophagus 2008, 21:409-415.

27. Cinti C, Vindigni C, Zamparelli A, La Sala D, Epistolato MC, Marrelli D, Cevenini G, Tosi P: Activated Akt as an indicator of prognosis in gastric cancer. Virchows Arch 2008, 453:449-455.

28. Pappas G, Zumstrin LA, Munshi A, Hobbs M, Meyn RE: Adenoviralmediated PTEN expression radiosensitizes non-small cell lung cancer cells by suppressing DNA repair capacity. Cancer Gene Therapy 2007, 14:543-549

29. Wickramasinghe NS, Manavalan TT, Dougherty SM, Riggs KA, Li Y, Klinge $C M$ : Estradiol downregulates miR-21 expression and increases miR-21 target gene expression in MCF-7 breast cancer cells. Nucleic Acids Research 2009, 37:2584-2595.

30. Qi L, Bart J, Tan LP, Platteel I, Sluis T, Huitema S, Harms G, Fu L, Hollema H, Berg A: Expression of miR-21 and its targets (PTEN, PDCD4, TM1) in flat epithelial atypia of the breast in relation to ductal carcinoma in situ and invasive carcinoma. BMC Cancer 2009, 9:163.

31. Talotta F, Cimmino A, Matarazzo MR, Casalino L, De Vita G, D'Esposito M, Di Lauro R, Verde P: An autoregulatory loop mediated by miR-21 and PDCD4 controls the AP- 1 activity in RAS transformation. Oncogene 2009, 28:73-84.

32. Vinciguerra M, Sgroi A, Veyrat-Durebex C, Rubbia-Brandt L, Buhler LH, Foti $M$ : Unsaturated fatty acids inhibit the expression of tumor suppressor phosphatase and tensin homolog (PTEN) via MicroRNA-21 upregulation in hepatocytes. Hepatology 2009, 49:1176-1184.

33. Yang H, Kong W, He L, Zhao JJ, O'Donnell JD, Wang J, Wenham RM, Coppola D, Kruk PA, Nicosia SV, Cheng JQ: MicroRNA expression profiling in human ovarian cancer: miR-214 induces cell survival and cisplatin resistance by targeting PTEN. Cancer Res 2008, 68:425-433.

34. Zhang JX, Han L, Ge YL, Zhou X, Zhang AL, Zhang CZ, Zhong Y, You YP, Pu $P Y$, Kang CS: miR-221/222 promote malignant progression of glioma through activation of the Akt pathway. Int J Oncol 2010, 36:913-920.
35. Ramkissoon SH, Mainwaring LA, Sloand EM, Young NS, Kajigaya S: Nonisotopic detection of microRNA using digoxigenin labeled RNA probes. Mol Cell Probes 2006, 20:1-4.

36. Wang X, Tang S, Le SY, Lu R, Rader JS, Meyers C, Zheng ZM: Aberrant expression of oncogenic and tumor-suppressive microRNAs in cervical cancer is required for cancer cell growth. PLoS One 2008, 3:e2557.

37. Ito H, Kanzawa T, Miyoshi T, Hirohata S, Kyo S, Iwamaru A, Aoki H, Kondo Y, Kondo S: Therapeutic efficacy of PUMA for malignant glioma cells regardless of the p53 status. Hum Gene Ther 2005, 16:685-698.

38. Wang Y, Lee CG: MicroRNA and cancer-focus on apoptosis. J Cell Mol Med 2009, 13:12-23.

39. Kim RH, Mak TW: Tumours and tremors: PTEN regulation underlies both. Br J Cancer 2006, 94:620-624

40. He XC, Yin T, Grindley JC, Tian Q, Sato T, Tao WA, Dirisina R, PorterWestpfahl KS, Hembree M, Johnson T, Wiedemann LM, Barrett TA, Hood L, Wu H, Li L: PTEN-deficient intestinal stem cells initiate intestinal polyposis. Nat Genet 2007, 39:189-198.

41. Guo J, Miao Y, Xiao B, Huan R, Jiang Z, Meng D, Wang Y: Differential expression of microRNA species in human gastric cancer versus nontumorous tissues. J Gastroenterol Hepatol 2009, 24:652-657.

42. Kim YK, Yu J, Han TS, Park SY, Namkoong B, Kim DH, Hur K, Yoo MW, Lee HJ, Yang HK, Kim VN: Functional links between clustered microRNAs: suppression of cell-cycle inhibitors by microRNA clusters in gastric cancer. Nucleic Acids Res 2009, 37:1672-1681.

43. Honjo S, Osaki M, Ardyanto TD, Hiramatsu T, Maeta N, Ito H: COX-2 inhibitor, NS398, enhances Fas-mediated apoptosis via modulation of the PTEN-Akt pathway in human gastric carcinoma cell lines. DNA Cell Biol 2005, 24:141-147.

44. Byun DS, Cho K, Ryu BK, Lee MG, Park Jl, Chae KS, Kim HJ, Chi SG: Frequent monoallelic deletion of PTEN and its reciprocal association with PIK3CA amplification in gastric carcinoma. Int J Cancer 2003, 104:318-327.

45. Oki E, Baba H, Tokunaga E, Nakamura T, Ueda N, Futatsugi M, Mashino K, Yamamoto M, Ikebe M, Kakeji Y, Maehara Y: Akt phosphorylation associates with LOH of PTEN and leads to chemoresistance for gastric cancer. Int J Cancer 2005, 117:376-380

46. Yu HG, Ai YW, Yu LL, Zhou XD, Liu J, Li JH, Xu XM, Liu S, Chen J, Liu F, Qi YL, Deng QJ, Cao J, Liu SQ, Luo HS, Yu JP: Phosphoinositide 3-kinase/Akt pathway plays an important role in chemoresistance of gastric cancer cells against etoposide and doxorubicin induced cell death. Int J Cancer 2008, 122:433-443.

47. Itoh N, Semba S, Ito M, Takeda H, Kawata S, Yamakawa M: Phosphorylation of Akt/PKB is required for suppression of cancer cell apoptosis and tumor progression in human colorectal carcinoma. Cancer 2002, 94:3127-3134.

48. Liao Y, Grobholz R, Abel U, Trojan L, Michel MS, Angel P, Mayer D: Increase of AKT/PKB expression correlates with Gleason pattern in human prostate cancer. In J Cancer 2003, 107:676-680.

49. kudela K, Hayashi H, Ito T, Yazawa T, Suzuki T, Nakane Y, Sato H, Ishi H, Keqin X, Masuda A, Takahashi T, Kitamura H: K-ras gene mutation enhances motility of immortalized airway cells and lung adenocarcinoma cells via Akt activation: possible contribution to noninvasive expansion of lung adenocarcinoma. Am J Pathol 2004, 164:91-100.

50. Vasko V, Saji M, Hardy E, Kruhlak M, Larin A, Savchenko V, Miyakawa M, Isozaki O, Murakami H, Tsushima T, Burman KD, De Micco C, Ringel MD: Akt activation and localisation correlate with tumour invasion and oncogene expression in thyroid cancer. J Med Genet 2004, 41:161-170,

51. Grille SJ, Bellicosa A, Upson J, Klein-Szanto AJ, Van RF, Lee KW, Donowitz $M$, Tsichlis PN, Larue L: The protein kinase Akt induces epithelial mesenchymal transition and promotes enhanced motility and invasiveness of squamous cell carcinoma lines. Cancer Res 2003, 63:2172-2178

52. Brognard J, Clark AS, Ni Y, Dennis PA: Akt/protein kinase B is constitutively active in non-small cell lung cancer cells and promotes cellular survival and resistance to chemotherapy and radiation. Cancer Res 2001, 61:3986-3997.

53. Tanno S, Yanagawa N, Habiro A, Koizumi K, Nakano Y, Osanai M, Mizukami Y, Okumura T, Testa JR, Kohgo Y: Serine/threonine kinase AKT is frequently activated in human bile duct cancer and is associated with increased radioresistance. Cancer Res 2004, 64:3486-3490. 
54. Garofalo M, Di Leva G, Romano G, Nuovo G, Suh SS, Ngankeu A, Taccioli C, Pichiorri F, Alder H, Secchiero P, Gasparini P, Gonelli A, Costinean S, Acunzo M, Condorelli G, Croce CM: miR-221 \& 222 regulate TRAIL resistance and enhance tumorigenicity through PTEN and TIMP3 downregulation. Cancer Cell 2009, 16:498-509.

55. Park JK, Jung HY, Park SH, Kang SY, Yi MR, Um HD, Hong SH: Combination of PTEN and gamma-ionizing radiation enhances cell death and $\mathrm{G}(2)$ / $M$ arrest through regulation of AKT activity and p21 induction in nonsmall-cell lung cancer cells. Int J Radiat Oncol Biol Phys 2008, 70:1552-1560.

56. Milas L, Akimoto T, Hunter NR, Mason KA, Buchmiller L, Yamakawa M, Muramatsu H, Ang KK: Relationship between cyclin D1 expression and poor radioresponse of murine carcinomas. Int J Radiat Oncol Biol Phys 2002, 2:514-521.

57. Zhang C, Kang C, You Y, Pu P, Yang W, Zhao P, Wang G, Zhang A, Jia Z, Han L, Jiang H: Co-suppression of miR-221/222 cluster suppresses human glioma cell growth by targeting p27kip1 in vivo and in vivo. Int $\mathrm{J}$ Oncol 2009, 34:1653-1660.

58. Fornari F, Gramantieri L, Ferracin M, Veronese A, Sabbioni S, Calin GA, Grazi GL, Giovannini C, Croce CM, Bolondi L, Negrini M: MiR-221 controls CDKN1C/p57 and CDKN1B/p27 expression in human hepatocellular carcinoma. Oncogene 2008, 27:5651-5661.

59. Lu Y, Xiao J, Lin H, Bai Y, Luo X, Wang Z, Yang B: A single anti-microRNA antisense oligodeoxyribonucleotide(AMO) targeting multiple microRNAs offers an improved approach for microRNA interference. Nucleic Acids Research 2009, 37:e24.

60. Esau CC: Inhibition of microRNA with antisense oligonucleotides. Methods 2008, 44:55-60

\section{Pre-publication history}

The pre-publication history for this paper can be accessed here: http://www.biomedcentral.com/1471-2407/10/367/prepub

\section{doi: $10.1186 / 1471-2407-10-367$}

Cite this article as: Chun-zhi et al., MicroRNA-221 and microRNA-222 regu late gastric carcinoma cell proliferation and radioresistance by targeting PTEN BMC Cancer 2010, 10:367

Submit your next manuscript to BioMed Central and take full advantage of:

- Convenient online submission

- Thorough peer review

- No space constraints or color figure charges

- Immediate publication on acceptance

- Inclusion in PubMed, CAS, Scopus and Google Scholar

- Research which is freely available for redistribution

Submit your manuscript at www.biomedcentral.com/submit
C Biomed Central 